\title{
OPTIMASI HASIL PRODUKSI OLAHAN DAGING SAPI DENGAN MENGGUNAKAN LINEAR PROGRAMMING (STUDI KASUS : UD. ANGKASA TIMOR KUPANG)
}

\author{
V. S. Adoe ${ }^{1}$ \\ 1Program Studi Teknik Informatika STIKOM Artha Buana Kupang \\ JIn. Samratulangi III No. 1 Walikota Kupang - NTT, 85111 \\ 1veraanwar08@gmail.com
}

\begin{abstract}
UD. Angkasa Timor is one of the business units engaged in beef processing with 3 forms of products produced, se'i, beef jerky and shredded beef. The obstacle faced is that entrepreneurs have not used the available resources optimally so the benefits have not been maximized. Therefore, this study aims to combine existing production resources so that entrepreneurs can obtain optimal production results and can obtain maximum profits. By using linear programming methods in the POM-QM For Windows V4 application, the analysis results are obtained X1 = $0.8571 \mathrm{~kg}, \mathrm{X} 2=1.8033 \mathrm{~kg}$, and X3 $=0.2459 \mathrm{~kg}$, with an Z value or an optimal profit of Rp. 7,197,893,
\end{abstract}

Keywords : : Linear Programming, Optimization

\section{ABSTRAK}

UD.Angkasa Timor merupakan salah satu unit usaha yang bergerak di bidang pengolahan daging sapi dengan 3 bentuk produk yang dihasilkan yaitu se'i, dendeng dan abon sapi. Kendala yang dihadapi adalah pengusaha belum menggunakan sumber daya yang tersedia secara optimal sehingga keuntungan yang diperoleh belum maksimal. Oleh karena itu, penelitian ini bertujuan untuk mengkombinasikan sumber daya produksi yang ada sehingga pengusaha dapat memperoleh hasil produksi yang optimal dan dapat memperoleh keuntungan yang maksimal. Dengan menggunakan metode linear programming dalam aplikasi POM-QM For Windows V4, diperoleh hasil analisis $X_{1}=0,8571 \mathrm{~kg}, X_{2}=1,8033 \mathrm{~kg}$, dan $X_{3}=0,2459 \mathrm{~kg}$, dengan nilai $Z$ atau keuntungan optimal sebesar Rp 7.197.893,-

Kata Kunci : Linear Programming, Optimasi 


\section{PENDAHULUAN}

\subsection{Latar Belakang}

Tingkat kebutuhan masyarakat akan gizi yang seimbang menyebabkan peningkatan akan kebutuhan pangan menjadi meningkat pula. Daging merupakan salah satu bentuk bahan pangan penting yang diperlukan dalam memenuhi kebutuhan gizi dimaksud. Selain mutu proteinnya tinggi, dalam daging juga terdapat kandungan lemak, mineral dan zat gizi lain yang lengkap dan seimbang, misalnya daging sapi.

Seiring dengan kemajuan ilmu pengetahuan dan teknologi saat ini, daging sapi mentah telah banyak diolah baik menjadi produk setengah jadi maupun produk jadi untuk dikonsumsi. Produk setengah jadi berupa potongan-potongan daging kecil yang masih harus diolah lebih lanjut sebelum dikonsumsi, misalnya daging cincang, potongan daging rendang, potongan daging "semur", potongan daging "sup", kikil dan lain-lain. Sedangkan produk jadi misalnya daging bakso, se'i, dendeng, abon, corned, dan sebagainya. Daging sapi juga dapat diolah dengan cara dimasak, digoreng, dipanggang, disate, diasap, atau diolah menjadi produk lain yang menarik antara lain daging korned, sosis, dendeng, dan abon. Primadewi (2018) mengemukakan, daging sapi juga dapat diolah dengan cara dimasak, digoreng, dipanggang, disate, diasap, atau diolah menjadi produk lain yang menarik antara lain daging korned, sosis, dendeng, dan abon. Pengolahan produk daging sapi tersebut selain mampu meningkatkan harga jual, diharapkan mampu meningkat pendapatan.

Nusa Tenggara Timur (NTT) merupakan salah satu provinsi di Indonesia yang menjadi produsen atau penghasil ternak sapi potong yang cukup besar. Menurut Data BPS Provinsi NTT, produksi ternak sapi potong di NTT pada tahun 2018 sebesar 1.027 .256 ekor sedangkan Kota Kupang sendiri sebesar 6.323 ekor. Hal ini berarti ternak sapi potong lebih besar diproduksi oleh kabupaten-kabupaten lain di NTT selain dari Kota Kupang. Untuk produksi daging sapi sendiri, NTT menghasilkan produk daging sapi sebanyak $11.761 .395 \mathrm{~kg}$ di tahun 2018. Sedangkan untuk Kota Kupang sebanyak $2.297 .700 \mathrm{~kg}$. Jumlah produksi tersebut seimbang dengan masyarakat NTT termasuk masyarakat Kota Kupang, yang juga menjadikan daging sapi sebagai salah satu sumber makanan yang penting sehari-hari.

UD ANGKASA TIMOR merupakan salah satu unit usaha, yang memproduksi beberapa bentuk olahan daging sapi yaitu, Se'i Sapi, Abon Sapi, dan Dendeng Sapi. Ketiga produk ini sangat digemari konsumen, baik itu masyarakat Kota Kupang pada umumnya terlebih masyarakat sekitar tempat usaha. Kendala yang dihadapi pengusaha adalah ketersediaan daging sapi untuk diolah yang terbatas sedangkan kebutuhan akan produk olahan daging sapi ini cukup tinggi. Oleh karena itu, pengusaha perlu merencanakan kombinasi input yang tepat 
dalam hal ini daging sapi agar keuntungan yang diperoleh menjadi optimal. Pada dasarnya, Linear Programming merupakan suatu model umum yang dapat digunakan dalam memecahkan masalah-masalah pengalokasian sumber-sumber yang terbatas secara optimal. Menurut Akram, Sahari and Jaya (2016), sebuah bentuk analisis perencanaan secara matematis, yang bertujuan untuk mendapatkan beberapa alternatif pemecahan masalah yang ada. Dengan demikian, optimasi dengan menggunakan metode linear programming diharapkan dapat memberi solusi penyelesaian dari permasalahan tersebut.

\subsection{Rumusan Masalah}

Bagaimana mengkombinasikan input-input produksi yang ada sehingga pengusaha dapat memperoleh hasil produksi yang optimal guna memperoleh keuntungan yang maksimal.

\subsection{Tujuan Penelitian}

Berdasarkan rumusan masalah di atas maka tujuan yang ingin dicapai dalam penelitian ini adalah untuk mendapatkan hasil produksi yang optimal dari kombinasi input-input produksi yang ada secara tepat, sehingga keuntungan yang diperoleh dapat maksimal.

\section{METODE PENELITIAN}

\subsection{Prosedur Penelitian}

Penelitian ini dilaksanakan pada UD ANGKASA TIMOR Kota Kupang. Data dikumpulkan dengan menggunakan beberapa metode antara lain :

1. Observasi atau pengamatan langsung proses kerja produk baik se'i, dendeng maupun abon.

2. Wawancara dan pengisian kuisioner dengan pemilik usaha maupun pekerja pada usaha tersebut.

Adapun data-data yang dibutuhkan untuk penelitian ini berupa data :

1. Jenis Produksi

2. Jumlah produk yang dihasilkan dalam sekali produksi

3. Jenis-jenis sumber daya atau bahan baku (input produksi) yang digunakan dan jumlah yang digunakan beserta stok atau jumlah yang tersedia.

4. Jumlah jam kerja per produksi.

5. Rata-rata keuntungan yang diterima dari hasil produksi tersebut.

Data yang dikumpulkan, kemudian dianalisis menggunakan aplikasi POM-QM untuk mengetahui hasil yang optimal. 


\subsection{Metode}

\subsubsection{Optimasi}

Optimasi adalah suatu tindakan atau proses untuk mencapai hasil yang ideal atau solusi yang dianggap optimal. Menurut Kamus Besar Bahasa Indonesia Online, optimasi dapat diartikan sebagai suatu bentuk mengoptimalkan sesuatu hal yang sudah ada, ataupun merancang dan membuat sesusatu secara optimal. Dengan demikian, optimasi merupakan suatu proses mengoptimalkan sumber daya ada guna mencapai keuntungan yang maksimal. Aprilyanti (2019) dalam penelitiannya yang berjudul Optimasi Keuntungan Produksi Pada Industri Kayu PT. Indopal Harapan Murni Menggunakan Linear Programming menjelaskan bahwa penyelasaian masalah optimasi dengan sumber daya yang terbatas adalah dengan pendekatan metode pemrograman dimana maximisasi atau minimisasi fungsi tujuan bergantung pada jumlah variabel input. Fungsi tujuan (objective function) adalah rumusan fungsi yang menjadi sasaran untuk mencapai penyelesaian optimum, sedangkan fungsi batasan (constraints function) merupakan rumusan dari sumberdaya yang tersedia, yang membatasi proses optimasi.

\subsubsection{Linear Programming}

Linear Programming merupakan suatu teknik dalam pengambilan keputusan alokasi sumber daya-sumber daya yang langka secara optimum (Syaifuddin T, 2011). Linear programming merupakan suatu model analisis matematika dalam menentukan pemecahan masalah yang optimal, dengan tujuan untuk maximisasi atau minimisasi sumber daya dengan batasan-batasan tertentu. Ada tiga unsur utama untuk menyelesaikan suatu permasalahan produksi, yaitu variabel keputusan, fungsi tujuan, dan fungsi kendala yang harus mempunyai karakteristik linear, (Indah and Sari, 2019). Linear programming harus memenuhi tiga kondisi antara lain :

1. Variabel keputusan (decision variables) merupakan variabel yang nilai-nilainya ditentukan untuk membuat keputusan. Variabel-variabel keputusan yang terlibat harus bernilai positif.

2. Kriteria-kriteria untuk memilih nilai terbaik dari variabel keputusan dapat diekspresikan sebagai fungsi linier. Fungsi kriteria ini bisa disebut fungsi objektif atau fungsi tujuan. Fungsi tujuan (objective function) adalah fungsi yang akan dioptimasi (dimaksimumkan atau diminimumkan)

3. Aturan-aturan operasi yang mengarahkan proses-proses dapat diekspresikan sebagai suatu set persamaan atau pertidaksamaan linier. Set tersebut dinamakan fungsi pembatas (constraints) yaitu pembatasan-pembatasan yang harus dipenuhi, (Saryoko, 2016). 


\section{HASIL DAN PEMBAHASAN}

\subsection{Hasil}

Berdasarkan hasil observasi, wawancara dan pengisian kuisioner dengan pengusaha dan pekerja pada UD. ANGKASA TIMOR diperoleh informasi sebagai berikut :

Tabel 1 : Hasil Tabulasi Data

\begin{tabular}{|l|l|l|l|l|l|}
\hline \multirow{2}{*}{$\begin{array}{l}\text { Bahan Bahan } \\
\text { Produksi }\end{array}$} & \multicolumn{3}{|l|}{ Jenis-Jenis Olahan Daging } & Persediaan & \multirow{2}{*}{ Satuan } \\
\cline { 2 - 4 } & Se'i & Dendeng & Abon & Maksimal & \\
\hline Daging Sapi & 70 & 50 & 40 & 160 & $\mathrm{Kg}$ \\
\hline Garam & 1,5 & 1,2 & 1 & 5 & $\mathrm{Kg}$ \\
\hline Gula & 0 & 10 & 8 & 20 & $\mathrm{Kg}$ \\
\hline Ketumbar & 0 & 0,7 & 0,3 & 2 & $\mathrm{Kg}$ \\
\hline Lada & 0 & 0,5 & 0 & 1 & $\mathrm{Kg}$ \\
\hline Bawang Merah & 0 & 1,5 & 2 & 5 & $\mathrm{Kg}$ \\
\hline Bawang Putih & 0 & 0,7 & 0,6 & 4 & $\mathrm{Kg}$ \\
\hline Gula Lempeng & 0 & 1 & 0 & 2 & $\mathrm{Kg}$ \\
\hline Santan & 0 & 0 & 2 & 2 & $\mathrm{Liter}$ \\
\hline Kayu Api & 50 & 0 & 35 & 100 & $\mathrm{Ikat}$ \\
\hline Lama Kerja & 16 & 8 & 16 & 50 & Jam \\
\hline Hasil Produksi & 40 & 30 & 25 & - & $\mathrm{Kg}$ \\
\hline Keuntungan & $\mathrm{Rp}$. & $\mathrm{Rp}$. & $\mathrm{Rp}$. & - & - \\
& 2.000 .0 & 2.700 .00 & 2.500 .0 & & \\
\hline & 00. & 0. & 00 & & \\
\hline
\end{tabular}

Sumber : Data olahan UD. Angkasa Timor Kupang 2019

Dari Tabel 1, maka input-input produksi yang digunakan kemudian diformulasikan secara matematis dengan menggunakan sistem linear programming sebagai berikut :

a. Variabel Keputusan.

Dari studi kasus di atas menunjukkan bahwa UD. ANGKASA TIMOR memproduksi 3 jenis produk yaitu :

$\mathrm{X}_{1}=\sum$ produk Se'i dalam sekali produksi

$\mathrm{X}_{2}=\sum$ produk Dendeng dalam sekali produksi

$\mathrm{X}_{3}=\sum$ produk Abon dalam sekali produksi 
b. Fungsi Tujuan.

Yang menjadi tujuan perusahaan pastinya adalah keuntungan yang maksimal. Oleh karena itu, fungsi tujuan dirumuskan :

$Z=2.000 .000 X_{1}+2.700 .000 X_{2}+2.500 .000 X_{3}$

c. Fungsi Kendala.

Yang menjadi kendala atau batasan masalah dalam studi kasus ini adalah sumber daya atau input yang digunakan dalam produksi daging se'i, dendeng maupun abon. Input - input atau sumber daya tersebut, kemudian dirumuskan secara matematis sebagai berikut :

$70 X_{1}+50 X_{2}+40 X_{3} \leq 160$

$1,5 X_{1}+1,2 X_{2}+X_{3} \leq 5$

$10 x_{2}+8 X_{3} \leq 20$

$0,7 X_{2}+0,3 X_{3} \leq 2$

$0,5 X_{2} \leq 1$

$1,5 X_{2}+2 X_{3} \leq 5$

$0,7 X_{2}+0,6 X_{3} \leq 4$

$\mathrm{X}_{2} \leq 2$

$2 x_{3} \leq 2$

$50 X_{1}+35 X_{3} \leq 100$

$16 X_{1}+8 X_{2}+16 X_{3} \leq 50$

Dengan syarat $X_{1}, X_{2}, X_{3} \geq 0$

Formulasi matematis di atas, lalu dianalisis untuk mendapatkan hasil penyelesaiannya dengan menggunakan aplikasi POM-QM for Windows V4. Adapun langkah-langkah dalam penggunaan aplikasi sebagai berikut :

1. Aktifkan aplikasi POM-QM for Windows V4, kemudian memilih module linear programming seperti tampilan pada Gambar 1.

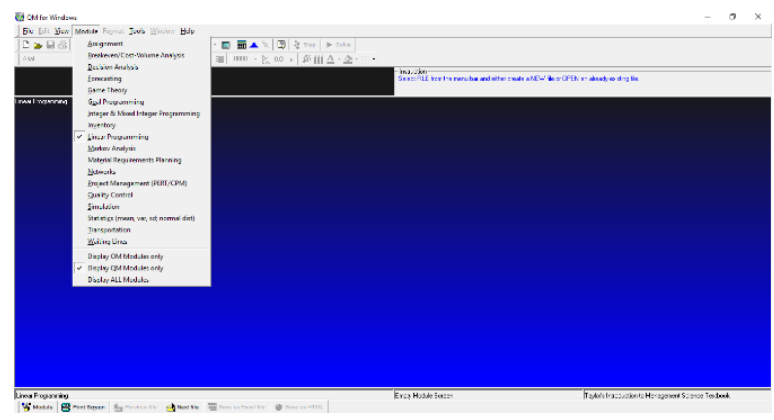

Gambar 1 : Tampilan Awal Program POM-QM 
2. Masukan semua formulasi matematis baik itu fungsi tujuan maupun fungsi kendala ke dalam aplikasi yang ditunjukkan pada Gambar 2.

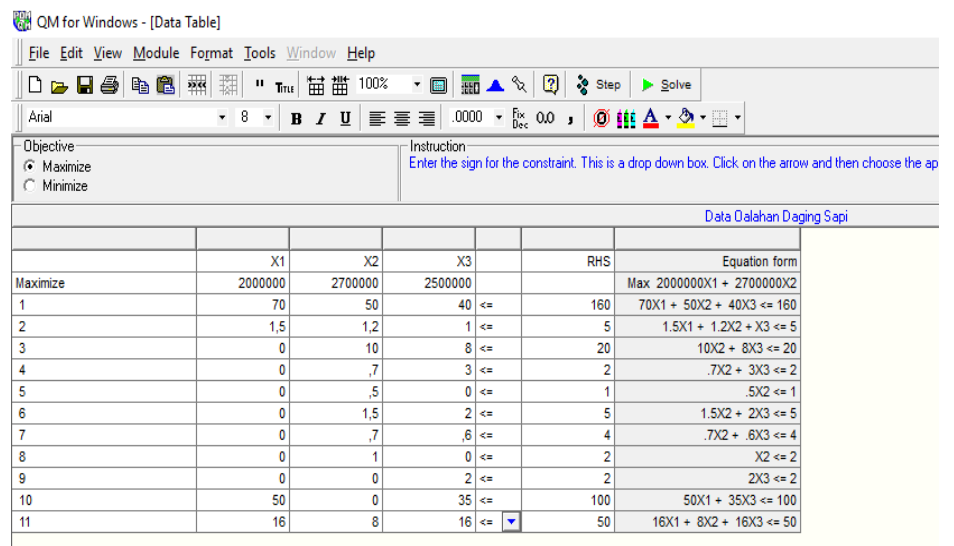

Gambar 2 : Tabel Data POM-QM

3. Langkah terakhir adalah menganalisis data yang telah dimasukkan dengan menggunakan solve button untuk mendapatkan hasil atau solusi yang optimal seperti Gambar 3.

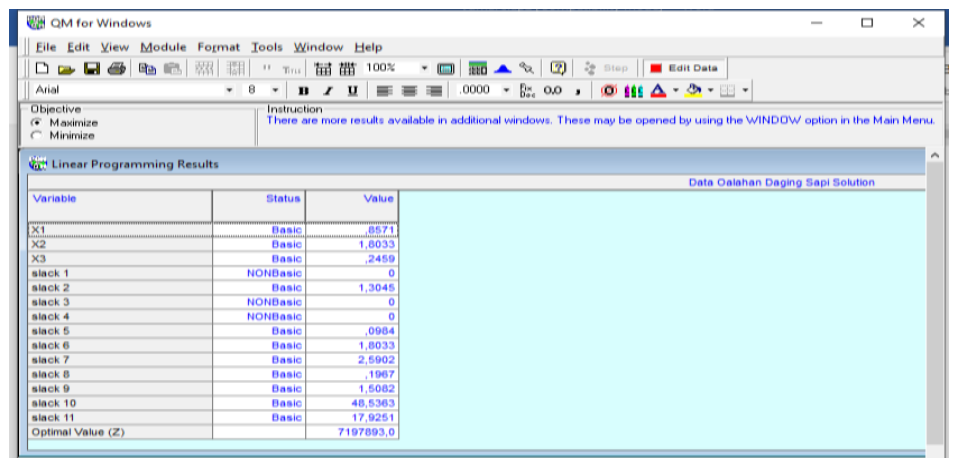

Gambar 3 : Linear Programming Result

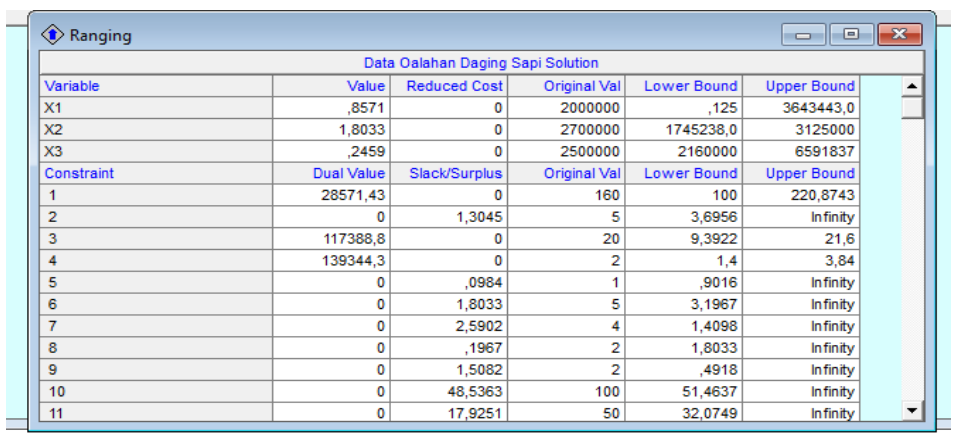

Gambar 4 : Ranging 


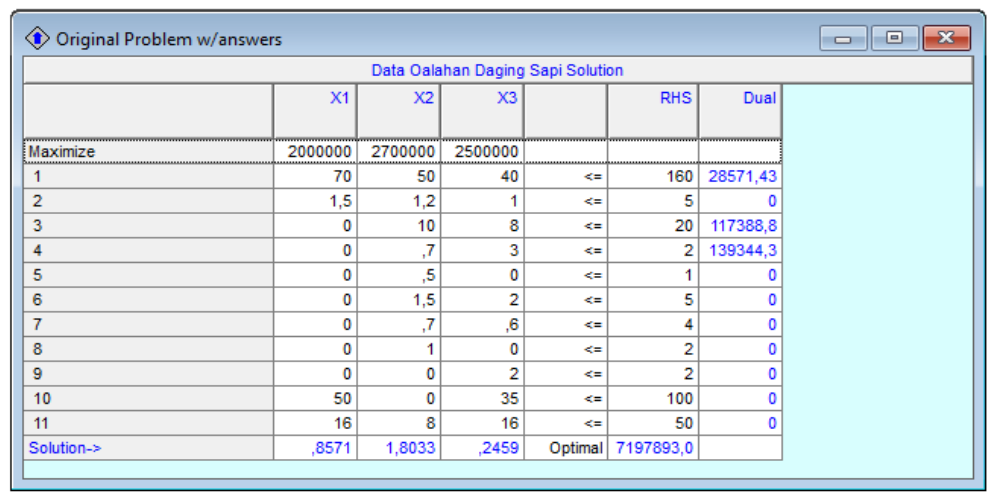

Gambar 5 : Original Problem W/Answears

\subsection{Pembahasan}

Pada Gambar 3 Linear Programming Result, diperoleh hasil analisis program yaitu produksi daging se'i $\left(X_{1}\right)=0,8571 \mathrm{~kg}$, produksi dendeng $\left(X_{2}\right)=1,8033 \mathrm{~kg}$, dan produksi abon $\left(X_{3}\right)=0,2459 \mathrm{~kg}$, dengan nilai $Z$ atau keuntungan sebesar Rp 7.197.893,-. Sedangkan pada Gambar 4. Ranging terlihat bahwa sumber daya atau constraint 1 (daging sapi), 3 (gula) dan 4 (ketumbar) habis terpakai, sedangkan sumber daya atau constraint yang lain tersedia berlebihan (garam, dll). Hasil ini menunjukkan bahwa produksi dendeng lebih banyak dibandingkan dengan se'i dan abon. Sedangkan data hasil tabulasi diperoleh hasil produksi se'i lebih banyak dibanding dendeng dan abon. Dari hasil ini dapat dijelaskan bahwa apabila pengusaha lebih banyak memproduksi dendeng sapi dibandingkan se'l dan abon maka maksimal keuntungan yang diperoleh sebesar Rp 7.197.893,-. Mengingat se'i juga termasuk produk yang tidak tahan lama disimpan maka sangat baik jika pengusaha mengurangi jumlah produksi se'i dan lebih banyak memproduksi dendang dan abon. Dengan demikian, ini merupakan suatu rekomendasi bagi pengusaha agar bisa mengkombinasikan input atau sumber daya yang dimiliki seoptimal mungkin untuk memperoleh hasil yang maksimal.

\section{KESIMPULAN}

Masalah optimasi penggunaan input atau sumber daya dengan menggunakan metode linear programming pada aplikasi POM-QM For Windows V4 dapat memberikan suatu rekomendasi kepada pengusaha untuk dapat mengkombinasikan sumber daya atau input produksi yang dimiliki secara tepat sehingga hasil berupa jumlah produksi dan keuntungan yang diperoleh menjadi maksimal. Hasil analisis POM-QM For Windows V4 untuk permasalahan UD. ANGKASA TIMOR diperoleh $\mathrm{X}_{1}=$ $0,8571 \mathrm{~kg}, X_{2}=1,8033 \mathrm{~kg}$, dan $X_{3}=0,2459 \mathrm{~kg}$, dengan nilai $Z$ atau keuntungan optimal sebesar $\mathrm{Rp}$ 7.197.893,-- 


\section{DAFTAR PUSTAKA}

[1] Akram, Sahari, A. and Jaya, A. . Optimalisasi Produksi Roti Dengan Menggunakan Metode Branch And Bound (Studi Kasus Pada Pabrik Roti Syariah Bakery, JI. Maleo, Lrg.VIII No. 68 Palu), Jurnal IImiah Matematika Dan Terapan (JIMT), 3, 2016, pp. 98-107.

[2] Aprilyanti, S. Optimasi Keuntungan Produksi Pada Industri Kayu PT. Indopal Harapan Murni Menggunakan Linear Programming, Jurnal Penelitian dan Aplikasi Sistem \& Teknik Industri (PASTI), XIII, 2019, pp. 1-8.

[3] Indah, D. R. and Sari, P. Penerapan Model Linear Programming Untuk Mengoptimalkan Jumlah Produksi Dalam Memperoleh Keuntungan Maksimal (Studi Kasus pada Usaha Angga Perabot), Jurnal Manajemen Inovasi (JMI), 10, 2019, pp. 98-115.

[4] Primadewi, I. , Analisis Nilai Tambah Industri Pengolahan Daging Sapi Menjadi Abon Di Kota Mataram, 2018, Universitas Mataram.

[5] Saryoko, A., Metode Simpleks Dalam Optimalisasi Hasil Produksi, Informaticds For Educators And Profesionals, 1, 2016, pp. 27-36.

[6] Syaifuddin T, D. , RISET OPERASI (Aplikasi Quantitative Analysis for Management), p. 147, Malang, 2011, Citra Malang. 